\title{
Study on the Plight and Countermeasures of Citizens' Participation in Municipal Administration
}

\author{
Jian-Qiang SUN ${ }^{\mathrm{a}}$, Li WANG ${ }^{\mathrm{b},{ }^{*}, \text { Si-Si CHEN }}{ }^{\mathrm{c}}$ \\ Jiangxi University of Traditional Chinese Medicine \\ a229419333@qq.com, b, $340088814 @ q q . c o m,{ }^{c} 1162429836 @ q q . c o m$
}

Li WANG*Corresponding author

\begin{abstract}
Keywords: Municipal administration, Citizens' participation, Citizen, Government.
\end{abstract}
\begin{abstract}
Citizens' participation is an important part of democratic politics. With the coordinated development of economy, politics and culture in our country, people's participation in urban management is getting higher and higher, and municipal managers are getting more and more aware of the government's position in municipal management In line with the requirements of democracy. However, when citizens participate in the municipal management system is still not sound, the participation of citizens in municipal administration in our country is only a lower level of participation. There are still many problems that need to be discussed and resolved. In this paper, the whole process of municipal management decisions were analyzed, which caused problems for citizens to participate in a comprehensive discussion of a variety of reasons, and from the democratic system, the public and the city management three proposed the countermeasures and suggestions to improve citizens' participation in municipal administration.
\end{abstract}

\section{Introduction}

The city is a hallmark of human civilization and a center of economic, political and social life for people. After the reform and opening up, China's cities have developed rapidly and the level of urbanization has risen significantly. Cities are increasingly becoming the center of modern economic activity. Cities not only have a vast market and advanced scientific and technological strength, but also have modern industries, transportation and convenient service industries. Various commercial activities and financial activities in the city are extremely active. Urban construction and management not only affect our quality of life, but also affect the future development of a city. The diversification of urban values, the diversification of demands, the improvement of democratic qualities and democratic awareness and the enhancement of participation awareness put forward new requirements on urban construction and management. As the main body of urban management, the government must be more flexible, more efficient, have a stronger ability to respond and innovate, and respond positively to citizens' demands. Government officials and their public service personnel need to rebuild their roles and strive to turn their traditional 'bureaucratic' thinking into a 'manager'.

Citizens' understanding of democracy is no longer the process of selecting their own opinion representatives to manage and determine state or local affairs, and relying on the bureaucratic management of public affairs. It is the citizen's right to participate in public affairs through autonomous communities and actually participate in the public affairs management process[1]. Since the 21 st century, urban development in our country has been maintaining a rapid pace. The solution to problems encountered in municipal construction is also becoming increasingly rational as the level of democracy rises. Under the background of democratic development, urban managers and citizens all rethink their roles in municipal administration. Democratic development undoubtedly greatly promoted the development of contemporary municipal construction to a more scientific and humane direction. 


\section{Related Concepts}

\section{Municipal Administration}

The city's healthy operation needs efficient urban management and service to support. Municipal administration based on the open and complex urban system of the city[2]. Based on the basic flow of urban information, the municipal administration uses decision-making, planning, organization, commandment, coordination and control to regulate and coordinate services and business operations through the interaction of government, market and society, economy and administrative technology. The core concept of modern municipal administration is to meet the needs of the public in urban to the greatest extent and to create an environment for the public to live and work in peace. With the rapid economic and social development in China and the ever-increasing standard of living of the people, the demand for creating a beautiful living environment also higher and higher. Under the new situation of municipal administration, we must adhere to the people-oriented principle, pay attention to improving the quality of service to the public, improve urban functions, improve the living environment, properly handle the relationship between man and man, man and society, man and nature, and jointly promote the building of a harmonious society, urban harmony. These are the source and goal of sustainable urban development[3].

\section{Citizens' Participation}

The subjects of citizen participation include individual citizens and citizens' organizations. Citizens' participation is not limited to the process of voting and selecting public agents, but also to the public policy implementation process. Even in accordance with the requirements of democratic governance, they act as government partners and provide public goods and services. The level of public participation has been gradually deepening from low to high, and its forms are becoming increasingly diversify. These include the direct participation of villagers' autonomy and residents' autonomy, the election of electoral deputies, the participation of democratic parties in political consultation, the participation of hearings, the participation of letters and visits, etc. The breadth and depth of citizen participation is an important measure of political development and political civilization in urban management[4]. It is an integral part of democratic politics and a basic way for citizens to participate in governance in the public sphere and affect public policies related to their interests[5].

\section{Present Situation and Plight}

\section{Citizens' Participation in Municipal Policy Decision Making}

China's economy has been growing steadily and its people's living standards have been raised. The urban management work has generally achieved good results. However, due to the limited level of social development, the decisions that undermine the credibility of the government also occur from time to time. City managers make mistakes in economic, educational, medical, or legal work. Some city managers lack awareness of 'people-oriented', do not care about the hardship of the masses, disregard of the strength of the people and financial resources and engage in performance-oriented projects and image projects[6]. Alternatively, directly hide the public, directly skip the public hierarchy for decision-making, and some even strive for their own interests and bring serious damage to the legitimate interests of the people. With the development of economy and society and the improvement of the quality of material life, citizens are paying more and more attention to traffic problems, housing problems, medical and health problems, urban environment and other issues in urban construction, especially those involving their own interests. However, the decision-making on such issues is often the last result that the public knows beforehand. Most of the problems such as the construction of urban traffic lines and the construction of housing have been formed after the scheme has been formed. Even after the project has been put into construction, 
citizens can grasp the information. The most directly related to the formulation of citizens' decision-making and the lack of public participation, urban planning out of the city reality. The interests of citizens contrary to the situation have occurred.

\section{Citizens' Participation in the Execution of Municipal Management Policy}

Policy implementation is a dynamic process. In the middle of implementation, we should not only pay attention to collecting information at any time, but also provide timely feedback. When the feedback shows that significant changes have taken place in the subjective and objective conditions set in the decision-making plan, special treatment will be required. If the implementation of the decision-making goals and programs require major adjustments, you need to re-decide. Therefore, in the middle of decision-making, communication with citizens is essential. However, due to the limited level of democratic development, people often cannot directly communicate their opinion on the mistakes made in the policy process. In the policy process, acts that infringe upon one's own interests often take simple and rude ways to resist.

\section{Citizens' Participation in Municipal Management Policy Assessment}

Through policy assessment, the degree to which urban policies are achieved and the expected results can be judged, which is also an effective way to rationally allocate policies. This plays an important role in the operation and orderly development of public policies, in achieving scientific democracy in public policies and in meeting the public interests and needs. Citizens are the most direct recipients of urban management policies and thus have the most say in urban policies. However, as China's municipal management policy assessment has not formed a scientific mechanism, many officials believe that the scientific formulation and operation of policies is an effective manifestation of the effectiveness of public policies. Moreover, it is considered that the assessment of urban policies is only a means of coping with the superior and the masses. In the assessment of policies, many governments lack a scientific attitude towards assessment and cannot effectively carry out policy assessment. Moreover, with their own authoritative formulation of policies, they seldom pay attention to the needs of the public and cause the public negatively meet the policy requirements.

\section{Citizens' Participation and Supervision in the Process of Municipal Administration}

The entire process of municipal administration needs timely correction of the behavior that is contrary to the purpose of the policy so as to achieve the preset goal. This needs to supervise all aspects of the formulation, implementation and feedback of urban management policies so as to ensure the rational utilization and effective allocation of urban resources. Urban managers undoubtedly play a crucial role in the process of supervision. However, if only the government supervises their own behaviors, it will inevitably lead to guarding against piracy and relaxation. Citizens have no means of obtaining the relevant information needed to supervise the government, making it difficult to implement them, leaving oversight to a mere formality. For a long time lack of supervision of the process of municipal administration, resulting in many administrative inefficiencies, or damage to the interests of citizens of administrative acts.

\section{Dilemma Cause Analysis}

\section{Perspective of Government}

The government generally initiates citizen's participation procedures and citizens are often passive in municipal administration. Civil rights and administrative power have obvious unequal, the executive power is higher than the public demand from start to finish. The large amount of information owned by the government in the decision-making stage cannot be shared with the public in a timely and accurate manner. The implementation of the government and the public communication channels are not smooth. The feedback phase of the government cannot reasonably deal with the public's response. Most importantly, municipal management activities often lead to unfair distribution. Specifically, urban resources are usually not concentrated in the hands of needy 
citizens, but concentrated on power or privilege. Because urban management policies essentially involve the redistribution of value and power, this redistribution provides just the opportunity to unfair and abuse of power. On the other hand, whether public policies of municipal administration can meet citizens' needs depends not only on policy design but also on policy implementation. In the process of implementation, policy mistakes may be found. However, the government departments are reluctant to suspend their original plans because of past planned resources. They are afraid of mishandling their policies. Therefore, citizens' participation and information feedback will be subjectively excluded in the process of policy implementation. As a result, they often result in greater losses.

\section{Perspective of the Public}

Citizens choose whether to participate or not, whether they participate actively or not, and make a comprehensive comparison of the costs involved. Citizens are only likely to take action if the benefits of participation exceed the costs to be met by the public or if they can learn of impunity. Citizen participation in urban management is now higher than in traditional urban management. However, the public's overall ability to participate in the administration of state affairs has not risen much. Long-standing official standard thinking has seriously inhibited the enthusiasm of citizens to participate. In addition, the reallocation of resources involved in urban management often does not have much impact on the personal interests of citizens. Because the costs of urban management policies are usually spread to many people, it makes citizens insensitive to these costs. In addition, due to the cost of participation, the results obtained are not individual and thus the 'free riding' mentality has virtually cultivated the thought of not getting things done[7]. Citizens' awareness of participation is weak, and most people only consider themselves as the objects of urban management, while neglecting themselves as important participants in urban management. In addition, citizens will ignore the relevant knowledge of urban management. Therefore, even if they provide urban management opportunities and encourage them to participate in urban construction, they will not be able to combine urban development with their own needs scientifically.

The main forms of citizen participation in urban management in our country include hearings, symposiums and suggestions on municipal administration through the media. This shows that the public participation in a single way, further illustrates the mechanism of our citizens to participate in urban management is imperfect. Moreover, public opinion supervision through the news media is only lagging behind. Late public participation in the public market is of no avail to the impact on urban construction and management, and the vast majority of the loss of profits caused by mistaken decision-making is irreparable.

\section{Citizens Participate in Municipal Management Strategies}

Citizen participation is an inevitable requirement of democracy and is conducive to the two-way coordinated development between citizens and the government. Democracy is the result of countless revolutions and reforms in the western countries. It has brought political civilization to a new height. The democratic ideas such as equality, freedom and human rights advocated by them provide an unprecedented way of thinking for safeguarding the interests of the majority of society. Our country draws lessons from the Western democratic system and establishes democracy with Chinese characteristics. However, under the conditions of the initial stage of socialism, there is still a long way to go to build China's democratic politics and there are many problems. The separation of government work from the masses, the conflict between government policies and the interests of the public, and the seriousness of the public's demands that it is hard to report to the government are serious. How to improve citizen participation in urban management is an issue that urban builders must tackle.

\section{Institutional Strategy}

Perfecting the systems and procedures for citizen participation can effectively protect citizens' political participation, make citizens more enthusiastic about participating in urban management, 
enhance people's sense of ownership, and enhance their ability to participate in the deliberations and administration of state affairs. The urban management policies formulated in this way are more conducive to the interests of citizens, so that the resistance of urban management policies in the later implementation process is greatly reduced.

Citizens to participate in urban management, not only in the process of participation, the legal process, but also the citizens of the municipal government's administrative supervision. The establishment of appropriate laws for the public to participate in the operation of the mechanism to provide legal protection is needed. A well-functioning civic engagement mechanism should cover many aspects of life. In addition, urban management system is an open decision-relevant information to the public, will directly affect the constraints of public municipal management decisions. Therefore, we must establish an open system of urban management information, the most important of which is to establish and improve the system of municipal information announcement, the hearing system, the open system of municipal documents, and the financial disclosure system[8]. Several forms of public participation are clarified with the requirements of institutionalization. Their specific applicability is analyzed. A procedural treatment mechanism is established to provide citizens with ways and means to ensure their participation in the process of urban management.

\section{Government's Strategy}

The implementation of municipal management and decision-making lies in the full understanding and support of the masses, starting from the interest of the masses. In the process of urban management, the government has always played a leading role. In order to realize the transformation of government's role, city managers should not only strengthen their self-construction, but also change their management methods and means. On the one hand, the government rearranges its own functions, including determining what should be done by the government and what should be delegated to non-governmental organizations or individuals. Thus concentrating more energy on strengthening the government's law enforcement capacity. On the other hand, government managers should comprehensively use all kinds of means to carry out municipal management, rather than confine them to coercive means. From management based mainly on administrative means to indirect management on the combination of administrative, legal, economic and other measures.

Therefore, the formulation and implementation of decision-making must pay attention to the following points: Adhere to the people-oriented concept of scientific development, co-ordinate the interests of the public and benefit the overwhelming majority of the public, not at the expense of the lawful interests of the minorities. The goal of making decisions is not to pursue economic development but to meet the material and spiritual needs of the citizens. All decisions and orders are formulated and implemented with full respect for citizens' opinions. Citizens should be encouraged to participate in the decision-making process, through various channels such as public discussion and consultation, to resolve mistakes in decision-making and improve their management level. The decision-making process is scientifically standardized, and public participation, expert consultation, risk assessment and group discussion are the necessary procedures of decision-making. Establish a correct view of political achievements, the economic development and public interest combined, performance measurement should be the unity of the two. Strengthen the public supervision, regular and irregular work inspection and opinion assessment. Comprehensively Improve the Scientific and Cultural Qualities and Professional Ethics of City Managers. Establish a decision-making tracking and evaluation mechanism to detect errors that are occurring in the process of implementing decision-making in a timely manner, and make timely adjustments or stop making mistakes.

\section{Citizens' Strategy}

The true subject of municipal management is a citizen, the lack of the main body of municipal management will be a failure of management. Increasing the level of citizen participation in municipal administration calls for arousal of public participation. At the same time, we must also raise the public's ability to participate in the deliberations and administration of state affairs.

Municipal administration has long been dominated by the government, and government 
departments seldom seek public opinion. Even if there is citizen participation in the management process, it is often initiated by the government, and citizens are not aware of the rights they have been given by law. This often leads to citizens losing their sense of responsibility to participate in city administration. In order to ensure citizens' long-term enthusiasm for participation, an incentive system can be set up. According to the suggestions made by the citizens in the process of participation or the importance of the information and the effects of the concrete application in practice, rewards are given to those who have made good suggestions or information. Thus, to stimulate public participation in municipal management process enthusiasm.

In addition, municipal administration not only requires a wide range of people who have the initiative to participate, but also requires a large number of citizens who have the expertise and ability to manage cities. To meet this requirement, it is necessary to raise the level of accumulation of people's relevant knowledge. First of all, through a variety of educational tools, increase the city's management expertise. We can hold relevant knowledge contests between communities or agencies and increase public enthusiasm for learning city management knowledge. Secondly, at the stage of compulsory education, children should be better informed about and mastered the city management expertise. We should directly reserve the next generation of talents for urban construction and management. Finally, it can also be initiated by the subdistrict offices, set up city management knowledge learning groups, and provide free city management knowledge. People are urged to apply knowledge in practice and to gain further knowledge of municipal administration.

\section{References}

[1]Sherry R. Arnstein, A Ladder of Citizen Participation[J].JAIP,Vol.35,No.4,July 1969.

[2]John C. Duncan, Jr. Multicultural Participation In The Public Hearing Process: Some Theoretical, Pragmatical, And Analeptical Considerations,24 Colum[J].Envtl.L.1999.P188-202.

[3]Qin Mu. Think Tanks in Germany Hinder the Cooperation between China and Germany[N].Global Time,2016.

[4]Outsider and Insider Expertise: The Response of Residents of Deprived Neighbourhoods to an Academic Definition of Social Exclusion[J]. Liz Richardson, Julian Le Grand. Social Policy \&Administration . 2002 (5)

[5] 'The impact of service experience and service type on citizen satisfaction with public services'. Trevor Brown. 2004 meetings of the Association, of Policy Analysis and Management.

[6]Effective Ways to Optimize Benefits of Citizens Participation in the Process of Government Performance Evaluation. Zhang Bo, Lu Gang. Northeast Normal University Journal. 2010

[7]Linking Citizen Satisfaction Data to Performance Measures: A Preliminary Examination. David Swindell, Janet M Kell. Pubic Performance \& Management Review. 2000

[8]An Analysis of Citizen Participation in Public Policy Making in China. Zhang Yi-min. Enterprise Herald. 2015 